\title{
aniki
}

Revista Portuguesa da Imagem em Movimento

Portuguese Journal of the Moving Image

\section{Filmar-se, Sendo: O tempo narrativo presente em documentários autobiográficos}

\author{
Gabriel Kitofi Tonelo \\ Universidade de São Paulo, Escola de Comunicação e Artes \\ gtonelo@gmail.com \\ https://orcid.org/oooo-0002-2896-1634
}

RESUMO Este artigo aborda como a noção de um presente narrativo se transpõe de maneira própria em documentários de teor autobiográfico e pessoal. Filmes nos quais cineastas-autobiógrafos buscam transpor o presente de uma experiência vivida para a narrativa a partir de metodologias imagético-sonoras sincrônicas surgem na cinematografia documentária mundial no final da década de 1960. Tais aspectos da transposição de um presente autobiográfico ainda permeiam a filmografia contemporânea e estão patentes na filmografia de diversos países. O artigo explica a transposição de aspectos do tempo presente em narrativas autobiográficas a partir de três perspectivas: (1) a cotidianidade como matéria-prima da narratividade autobiográfica; (2) a temporalidade cronológica como estrutura de referência e de apoio para a narrativa autobiográfica; (3) a interação dialógica entre cineasta e pessoas filmadas como manifestação do presente autobiográfico por meio da emersão de afetos.

PALAVRAS-CHAVE Documentário autobiográfico; temporalidade; narrativa; cronologia; cinema direto.

\section{Introdução}

Narrativas autobiográficas permeiam a história do cinema documentário há mais de meio século. ${ }^{1}$ Tais filmes que apontam tematicamente para um ou mais aspectos de uma vida vivida por um indivíduo que reconhecemos como a principal força criativa em sua feitura - um diretor ou uma diretora - são parte integrante de diversas

\footnotetext{
${ }^{1}$ Uma versão preliminar deste trabalho foi apresentada em forma de comunicação oral no XXIII Encontro da SOCINE (Porto Alegre, Brasil).
} 
filmografias nacionais nas últimas décadas. Michael Renov, um dos principais autores que escreveram sobre o tema, sugere que "a autobiografia fílmica existe de várias formas" (Renov 2014, 41). Ao longo desse período, a autobiografia no cinema pôde existir, segundo o autor, a partir de modalidades de construção narrativa diversas. Estiveram, entre elas, o ensaio fílmico, o ensaio eletrônico, o diário fílmico, a vídeo confissão, o modo epistolário e a etnografia doméstica.

A diversidade de construção narrativa em filmes de teor autobiográfico é detectável quando pensamos em obras que obtiveram maior destaque público, seja da crítica especializada, nos circuitos de festivais ou em estudos acadêmicos. Um caso como o de Silverlake Life: The View from Here (Tom Joslin e Peter Friedman, 1993) mostra como o sucesso da empreitada autobiográfica pode depender do uso da câmera de filmar (no caso de Joslin, da câmera de vídeo eletrônico) como vetor de evidência visível. A possibilidade que os espectadores tiveram de assistir ao adoecimento progressivo e à morte de Joslin - representada por seu corpo inerte, que vemos na tela -, a partir de uma narrativa autobiográfica, colaborou para o reconhecimento do filme como um potente produto cultural simbólico de sua época, em meio à crise do $\mathrm{HIV}^{2}$ A imprescindibilidade do registro por imagens e sons da qual depende Silverlake Life não acontece, por exemplo, em um documentário como Valsa com Bashir (Ari Folman, 2008). No caso, o diretor Ari Folman encontra na animação o vetor para a narrativa de busca por sua memória perdida a respeito de sua participação, como soldado israelense, na invasão do Líbano, em 1982, e sobre a possibilidade de ter estado presente no massacre de Sabra e Chatila.

Para além da diversidade formal, a perspectiva de tematização autobiográfica atraiu (e atrai) tanto cineastas ainda pouco conhecidos(as) publicamente e em início de carreira quanto diretores(as) com obras reconhecidas. Um cineasta como o estadunidense Ross McElwee talvez seja o principal exemplo do primeiro desses casos. Desconhecido do grande público até então, o lançamento de seu primeiro longa-metragem, Sherman's March (1986), projetou publicamente a carreira de McElwee e é um dos filmes

\footnotetext{
${ }^{2}$ Jim Lane evoca o momento em que Silverlake Life foi veiculado em rede televisiva nacional, sustentando que o visionamento do filme "influenciou a maneira que pensamos sobre o papel da autobiografia e do documentário na vida estadunidense contemporânea" (Lane 2002, 3). A recepção de Silverlake Life no âmbito do programa P.O.V. é também detalhado por Barbara Abrash (2007).
} 
responsáveis pela popularização do gênero. Desde então, McElwee consolidou-se como expoente do cinema autobiográfico, calcando toda sua obra subsequente em narrativas pessoais e em um processo contínuo que dura mais de três décadas e sete longas-metragens. Notase, em um movimento inverso, um caso como o da cineasta francobelga Agnès Varda. Diferentemente de McElwee, Varda enveredou de maneira mais adensada pela exploração autobiográfica quando já portava reconhecimento como um dos maiores nomes da filmografia mundial. Em um momento mais próximo do final de sua carreira e de sua vida, Varda explorou tematicamente aspectos de sua trajetória pública e privada - em filmes como As Praias de Agnès (2008), Visages, Villages (2017) ou Varda por Agnès (2019).

A breve explicação acima tem como propósito mencionar a multiplicidade de facetas a partir das quais a noção de autobiografia fílmica vem se apresentando na filmografia não-ficcional mundial nas últimas décadas. No caso da linha histórica do cinema documentário, tal tematização apresentou-se como novidade e tomou fôlego a partir do final da década de 1960 e em um âmbito universitário. Se as narratividades autobiográficas, naquele momento, eram vistas como inovações e estavam mais restritas às salas de cinema arthouse ou aos próprios ambientes das universidades, é possível dizer que tal modo de enunciação foi sendo difundido a públicos mais diversos e amplos ao longo das décadas seguintes. ${ }^{3}$ Hoje, narrativas que portam teor autobiográfico - a partir da proposição de Renov de que elas podem tomar diversas formas - são encontradas desde o circuito independente de festivais dedicados ao cinema documentário até às plataformas de streaming de amplo acesso.

A intenção deste artigo é a de voltar ao momento da história do cinema documentário em que as construções temáticas autobiográficas afloraram de maneira mais consistente como possibilidade. Partindo desse momento, buscarei contribuir com os estudos sobre

\footnotetext{
${ }^{3}$ Sherman's March é um exemplo de documentário que pioneiramente foi lançado no circuito comercial de cinema e obteve grande sucesso de público. Catherine Russell, inclusive, denomina o longa-metragem de McElwee como sendo um documentário autobiográfico mainstream (Russell 1999). Na década de 1990, filmes como Silverlake Life: The View from Here e Tongues Untied (Marlon Riggs, 1989) evidenciam como documentários com teor temático autobiográfico se projetaram no âmbito da televisão pública estadunidense e evocaram debates e reações enérgicas de um público menos fiel ao circuito de cinefilia de não-ficção. Mais recentemente, a indicação de um filme como Strong Island (Yance Ford, 2017) ao Oscar de Melhor Documentário também exemplifica o caminho de projeção pública que narratividades autobiográficas tiveram ao longo das décadas.
} 
documentários autobiográficos a partir de uma reflexão acerca de como a noção de tempo presente se manifesta narrativamente em tais filmes. Aquelas que buscarei evidenciar como sendo as manifestações do presente nesses filmes relacionam-se de maneira íntima com debates que permeavam o cinema documentário no final da década de 1960 sendo, portanto, um desdobramento em relação a eles. Por outro lado, o artigo refletirá sobre como o cinema documentário em sua virada moderna - a partir das possibilidades de registro imagético-sonoro sincrônico - pôde proporcionar narratividades autobiográficas que trabalham a mesma noção de tempo presente de modo distinto a outras linguagens de expressão narrativa como a literatura. A noção de tempo presente aplicada às narrativas documentárias autobiográficas não consiste em uma "modalidade" autobiográfica específica - como propõe Renov -, podendo ser visível em diversas delas e de maneira mais ou menos intensa em uma narrativa específica. Ainda que a análise parta de um ponto específico da história do cinema documentário, exemplificarei como as manifestações do tempo presente em narrativas autobiográficas acontecem em filmografias de países diversos e são detectáveis em filmes realizados em diferentes momentos, como também em uma filmografia contemporânea.

Este estudo sobre as manifestações do presente em narrativas autobiográficas paraleliza-se a outros trabalhos, lançados nas últimas duas décadas, que se detêm analiticamente em momentos originários da noção de autobiografia aplicada ao cinema documentário nos desdobramentos do cinema direto estadunidense, como também aos recentes trabalhos que oferecem reflexões sobre a construção de temporalidades em tais filmes. Jim Lane (2002) abordou de maneira mais detalhada títulos que, até o momento, haviam sido pouco analisados nos estudos dos cinemas em primeira pessoa, como também se empenhou em oferecer uma linha histórica a respeito do desenvolvimento de tal filmografia nos Estados Unidos da América. Especialmente importante para este trabalho é a maneira através da qual Lane situa como um dos inícios da história dos documentários autobiográficos no país os filmes produzidos na década de 1970 no âmbito universitário da região de Cambridge, Massachusetts, em duas de suas principais universidades: o MIT e a Harvard University. Anos depois, Scott MacDonald retoma a história do cinema autobiográfico de Cambridge (2013), sendo responsável por cunhar a expressão "a virada de Cambridge" ("the Cambridge turn"). Ampliando o trabalho de Lane, MacDonald enxerga uma linha histórica que conecta "gerações" de 
cineastas relacionados a tal região até o presente momento e cujas obras remetem ao pensamento sobre cinema autobiográfico originado em suas universidades.

A reflexão sobre a manifestação do presente em narrativas autobiográficas afilia-se, ainda, a trabalhos recentes que visam pensar a construção de temporalidades nesse tipo de cinema ou que resgatam historicamente a produção autobiográfica da década de 1970 em uma chave realista. Nadja Gernalzick (2014) dedica-se especificamente à reflexão acerca de tempos narrativos (narrative tenses) em documentários autobiográficos, considerando as propriedades da captação de imagem e som e a construção narrativa via montagem. $O$ trabalho de Gernalzick apresenta um denso caráter de análise gramatológica - com ênfase na decomposição estrutural e na materialidade semiótica - que este artigo visa complementar, oferecendo reflexões a respeito do tempo presente em narrativas autobiográficas a partir de um caráter de análise não apenas formal, mas também temático.

\section{Temporalidades narrativas: o presente em documentários autobiográficos}

Construções narrativas autobiográficas interseccionam-se de maneira mais consistente com a história do cinema documentário no final dos anos 1960. Ainda no início da década, inovações de ordem tecnológica como o aprimoramento, simplificação e miniaturização do aparato de registro imagético-sonoro sincrônico abriram portas para narrativas não-ficcionais que engajavam uma representação do mundo de maneira distinta da do documentarismo clássico. O cerne da construção narrativa de filmes ligados ao Cinema Direto estadunidense consistia na relação dialógica entre indivíduos e na tematização de suas experiências de habitar o mundo. Em pouco tempo, fatores como a acessibilidade trazida pelo novo aparato de registro fílmico e uma circunstância ideológica favorável - no caso dos Estados Unidos, a segunda onda do feminismo e a noção de que o privado seria político contribuíram para o estreitamento da relação entre cineasta e objeto, culminando na proliferação de narratividades tematicamente ligadas à vida dos(as) próprios(as) cineastas.

Desde então, a manipulação da experiência do tempo é uma das forças propulsoras da motivação artística de cineastas-autobiógrafos(as) que 
investigaram possibilidades de filmar a respeito de si. Elementos narrativos que abrangem desde os registros imagéticos-sonoros (as tomadas fílmicas $)^{4}$ até as trilhas musicais não-diegéticas, a narração em voz over e o processo de montagem particularizam, nos documentários autobiográficos, noções temporais como as de passado, presente e futuro. A partir de tais estratégias, cineastas-autobiógrafos(as) puderam criar narrativas que deram vazão a aspectos de uma vida vivida contemporaneamente ao registro fílmico (o presente), à experiência da memória e/ou da reminiscência em relação a passagens experenciadas anteriormente (o passado) ou, ainda, a uma projeção a um ponto do tempo ainda não alcançado (o futuro).

Especificamente, a preocupação deste artigo é a explicitação das maneiras através das quais a noção de tempo presente é manifestada em narrativas documentárias autobiográficas. Apresenta-se como tais filmes puderam trabalhar a noção de tempo presente a partir das materialidades trazidas pelo cinema - e, especificamente nesse caso, pelo cinema documentário em sua virada moderna. A questão adquire especial relevância quando é colocada ao lado de uma das definições fundantes da noção de autobiografia literária, lançada por Phillipe Lejeune, em um de seus textos mais célebres (2008). Para sua análise, Lejeune parte de uma definição de autobiografia como uma "narrativa retrospectiva em prosa que uma pessoa real faz de sua própria existência, quando focaliza sua história individual, em particular a história de sua personalidade" (Lejeune 2008, 14). Interessante para esta discussão a respeito do presente em narrativas documentárias autobiográficas é a ênfase dada por Lejeune ao caráter retrospectivo que compõe os textos dessa natureza. Mesmo na distinção feita pelo autor entre a noção de autobiografia e outras modalidades de escrita de si - como as memórias ou os diários -, Lejeune parte do pressuposto de que a autobiografia compreende uma narrativização que é realizada em tempo posterior ao dos eventos vividos e, ainda, em que uma parcela

\footnotetext{
${ }^{4}$ Utilizo o conceito de "tomada" segundo Fernão Pessoa Ramos, que o sustenta como um tipo de figuração do mundo que constitui caracteristicamente as imagens-câmera fílmicas (Ramos 2012). Segundo Ramos, a tomada é responsável por estruturar um movimento de figuração que "é singular à imagem-câmera e que outras imagens não possuem" (Ramos 2012, 21), sendo composta pela ação do corpo em movimento e por sua expressão. A relação entre a tomada fílmica e o desenrolar do presente no momento do registro é ressaltada pelo autor como cerne da mise-en-scène documentária: “A ação do corpo na tomada e a expressão de seu afeto pela fisionomia e pelo gestual constituem o umbigo da especificidade da encenação documentária que se constela concretamente (se afigura) no tempo presente, no transcorrer do presente enquanto franja de um acontecer" (Ramos 2012, 21).
} 
de uma experiência vivida fosse transposta em linguagem a partir do sistema simbólico das palavras.

Se as inovações tecnológicas vividas por tal momento do cinema documentário possibilitavam os registros imagéticos-sonoros sincrônicos de maneira dialógica e com ênfase no tempo presente, de que maneira poderiam ser incorporadas à tematização autobiográfica? Em outras palavras, poderia o cinema oferecer um tipo de perspectiva autobiográfica na qual as narrativas a respeito de si pudessem ser construídas de maneira não-retrospectiva? Muito antes do surgimento do cinema, narrativas literárias autobiográficas canônicas exploraram a relação existente entre uma vida que é vivida no tempo presente e sua apreensão pelos sentidos. É o caso, por exemplo, das Confissões, nas quais Santo Agostinho, em seu décimo primeiro livro, sugere uma relação entre o tempo presente da experiência vivida e o sentido da visão, ao descrever a "visão presente das coisas presentes" (Agostinho 1981, 309) como parte de sua percepção da temporalidade. Se parte da experiência fruitiva do presente depende de sentidos como a visão (e, podemos adicionar aqui, a audição), como o cinema possibilitaria um tipo de autobiografia em que a vida é vivida concomitantemente à construção narrativa?

A transposição do tempo presente em narrativas documentárias autobiográficas acontece de maneiras distintas. Esta relação é detectável em três perspectivas que podem ser complementares ou interseccionais. Tais perspectivas inserem-se no conjunto de escolhas estilísticas, metodológicas e temáticas proposto pelos filmes e podem apresentar-se concomitantemente em uma mesma narrativa. São elas: (1) a cotidianidade como matéria-prima da narratividade autobiográfica; (2) a temporalidade cronológica como estrutura de referência e de apoio para o registro imagético-sonoro sincrônico; (3) a interação dialógica entre cineasta e pessoas filmadas como manifestação do presente autobiográfico por meio da emersão de afetos.

\section{Cotidianidade como matéria-prima da narratividade autobiográfica}

Uma das transposições do tempo presente em narrativas autobiográficas acontece a partir da exploração temática da noção de cotidianidade. Cineastas-autobiógrafos(as) que trabalham tematicamente elementos de uma vida cotidiana oferecem aos 
espectadores um convite para que fruam as relações que mantém habitualmente com o mundo privado ao seu redor e com as pessoas que o integram. Cotidianidade, em tal contexto, refere-se ao conjunto de manifestações que estão imbuídas no transcorrer diário de uma vida individual. Por extensão, as manifestações cotidianas dizem respeito ao que não é extraordinário. Estão ligadas à ordem do comum e do banal, pela probabilidade de serem repetidas.

Para Rita Felski, a "vida cotidiana é a mais evidente, e, ainda, a mais enigmática das ideias" (2000, 77, tradução nossa). O cotidiano, segundo Felski, seria "o continuum essencial, dado como certo, de atividades mundanas que enquadra nossas incursões em mundos mais esotéricos ou exóticos. É a realidade inegociável final, a base inevitável para todas as outras formas de esforço humano" (Felski 2000, 77-78, tradução nossa). ${ }^{5}$ Sinônimas do habitual, ordinário e mundano, Felski sustenta que as práticas cotidianas podem ser pensadas em oposição à reflexão crítica e à especulação. O que está ligado ao cotidiano seria "sinônimo da 'atitude natural', ao invés da 'atitude teorética" e "[sinônimo] do reino do senso comum e daquilo que é dado como certo, ao invés do ceticismo obstinado" (Felski 2000, 79, tradução nossa). Ainda segundo Felski, a vida cotidiana é tipicamente distinguida, ou diferenciada, dos momentos excepcionais - como a batalha, a catástrofe e os feitos extraordinários. Pelo contrário, as atividades cotidianas definem-se por uma ausência de singularidade e de diferenciação: "é o ar que se respira, o pano de fundo dado como certo, a base do senso comum de todas as atividades humanas" (Felski 2000, 80, tradução nossa).

Cineastas-autobiógrafos(as) que lidam com a noção de cotidianidade convidam os(as) espectadores(as) à consideração de suas próprias figuras na apreciação de experiências de vida que, dia após dia, emergem da interação com as pessoas e com os ambientes que fazem parte de seus viveres cotidianos. Trata-se, em outras palavras, de um convite à consideração de uma vida que é por eles(as) vivida para além do ofício de cineasta. Cineastas, para além de o serem, carregam o

\footnotetext{
${ }^{5}$ Em sua análise, Felski aponta também o impulso analítico que busca inverter a percepção da cotidianidade como sítio do ordinário e repetível e que se investe em uma leitura do cotidiano como sinônimo de atos de resistência e de subversão - sendo a de Michel de Certeau, em A Prática da Vida Cotidiana, uma das mais conhecidas. Em sua visão, a autora sugere, contudo, que tais percepções frequentemente "perdem de vista as qualidades rotineiras, mundanas, tidas como certas e que parecem tão centrais para sua definição - a própria cotidianidade do cotidiano" (Felski 2000, 80, tradução nossa).
} 
substrato de uma experiência vivida cotidianamente, no momento em que decidem realizar uma narrativa autobiográfica. Tal substrato é composto por uma teia de atividades e relações interpessoais que tendem a estar presentes na matéria-viva de uma existência cotidiana. É por esse motivo que, enquanto espectadores, relacionamos as estruturas de nosso próprio substrato da vida cotidiana com a experiência que é registrada (e vivida) pelos(as) diretores(as).

A hipótese trabalhada por cineastas-autobiógrafos(as) que lidam com uma noção de cotidianidade apoia-se na crença de que o registro imagético-sonoro sincrônico a respeito de aspectos de uma vida por eles(as) experienciada corriqueiramente poderia revelar um extrato da vida cotidiana - no sítio daquilo que é mundano ou ordinário - de maneira distinta se comparada a um relato oral ou escrito de um indivíduo acerca da vida que vive diariamente. Nesse sentido, o ímpeto autobiográfico de um(a) cineasta - em outras palavras, o desejo inicial de filmar em uma perspectiva autobiográfica - é delimitado por uma circunstância espaçotemporal determinada. Por ser assim, o momento (e o espaço) da decisão de registrar aspectos de uma vida cotidiana é precedido pelo amplo substrato da vida vivida até então. A possibilidade de identificar aspectos corriqueiros, mundanos, habituais ou repetíveis na vida de um(a) cineasta, em uma narrativa autobiográfica, acontece apenas a partir do alicerce de tais aspectos em experiências anteriores ao ato de filmar. Susanna Egan define o substrato anterior da experiência de vida como a vida "pré-textual" ao mencionar narrativas cinematográficas autobiográficas que "posicionam a vida pré-textual como controladora da narrativa e usam o meio fílmico bastante explicitamente como maneira de registrar as surpresas da contingência" (Egan 1994, 611, tradução nossa). Dessa maneira, o substrato pré-textual instaura-se como ponto de referência a partir do qual as "surpresas da contingência" (o acaso, a indeterminação) são pontuadas de maneira narrativa após a decisão de filmar em uma perspectiva autobiográfica.

Filmes que lidam com a noção de um presente autobiográfico em uma perspectiva cotidiana tendem a suscitar a sensação de uma narrativa documentária que, constantemente, é transbordada por eventos e por relações que pertencem a estruturas de uma vida que foi vivida anteriormente à presença da câmera e, mesmo que flexionada por sua presença, poderia ser vivida independentemente dela. Cinematograficamente, a origem dos estudos relativos à exploração 
autobiográfica-cotidiana deu-se de maneira mais consistente na Costa Leste dos Estados Unidos na década de 1970. Em especial, tais estudos concentraram-se nas atividades do departamento de produção e pesquisa cinematográficas do MIT, o MIT Film Section. O departamento iniciou o que, mais tarde, foi nomeado como a "virada", ou a "escola", de Cambridge (no estado de Massachusetts), de um tipo de produção autobiográfica (cf. MacDonald 2013). Cineastas que fizeram parte desse momento reconheciam a perspectiva dialógica interrelacional entre cineasta $\mathrm{e}$ as pessoas à sua volta como parte fundamental da experiência cotidiana. Nesse sentido, a produção do MIT Film Section considerava o registro imagético-sonoro sincrônico como condição irrevogável para a empreitada autobiográfica. A irrevogabilidade do som sincrônico à tomada é o que distingue a produção de documentários autobiográficos, segundo autores como Jim Lane (2002) e Scott MacDonald (2013), da produção ligada ao domínio avant-garde ou experimental. Ed Pincus, um dos cineastas pioneiros da escola de Cambridge, reconhecia a metodologia do departamento como "um reino totalmente diferente" (Pincus 1977, 171) se comparada à produção de Stan Brakhage e outros.

Juntamente com Richard Leacock, Pincus foi um dos principais cineastas e teóricos do MIT Film Section. Seu diário filmado, Diaries (1971-1976), é o principal produto fílmico advindo das perspectivas conceituais e metodológicas do departamento. Em Diaries, Pincus buscou testar as possibilidades de uma narratividade autobiográfica alicerçada no tempo presente ao registrar cinco anos de um período particular de sua vida privada. Segundo Jim Lane, o filme de Pincus enfatiza a importância de tornar o cotidiano visível como uma maneira de explorar a natureza da subjetividade e das interações humanas. Ao empunhar a câmera (e o gravador de som) em situações integradas a seu cotidiano, o filme evidencia uma intenção autobiográfica que busca testar a sobreposição da tomada fílmica ao ato de viver (Lane 2002, 53). Em Diaries, o ímpeto autobiográfico de Pincus é moldado pela crença no substrato pré-textual como repositório de energia para sua transposição em forma narrativa. Essa energia é potencializada pelas possíveis transformações de tal substrato diante da passagem do tempo. O cenário pré-textual, em Diaries, é composto pela circunstância de crise privada experienciada por Pincus e sua família no momento da decisão de iniciar o projeto: um casal na faixa dos trinta anos (o cineasta e sua esposa, Jane) que vive o cenário contracultural pós-1968, nos anos da Guerra do Vietnã e da segunda onda do feminismo 
estadunidense, que mantém o desejo de experimentar valores sociais e familiares (como um casamento "aberto") diante do desafio de criar dois filhos pequenos e de progredir com suas carreiras de profissionais liberais. É esse substrato, potencialmente instável, para o qual os espectadores são constantemente remetidos ao assistirem ao desenrolar da narrativa.

Filmar em uma perspectiva cotidiana, no caso de Pincus, evidencia a transposição em imagens e sons de uma crise privada que é vivida para além do ímpeto autobiográfico. Embora a presença da câmera possa flexionar e potencializar a situação crítica - como evidenciado na própria narrativa -, ela também existe (ou existiria) independentemente dela. Trata-se de um desejo de narratividade autobiográfica no qual a câmera, como frisado, recorrentemente corre atrás da representação de uma crise que está instaurada. A vida como alicerce referencial da criação autobiográfica é endereçada por Susanna Egan: "Os cineastas utilizam a câmera, ademais, como que para dramatizar especificamente o espectro mais amplo do material original e a natureza aleatória do especular" (1994, 607, tradução nossa). Egan complementa: "a mobília, os aposentos, o cenário e as pessoas irrompem do quadro como um lembrete constante daquela experiência original a que a experiência filmada se refere" $(1994,607$, tradução nossa). Termos como "irromper" (to burst out), como o utilizado por Egan, endossam a potencialidade da câmera de filmar em transpor o substrato interpessoal da vida vivida por um(a) cineasta como principal subsídio para a narratividade autobiográfica. Trata-se de um tipo de narratividade que se apoia no vínculo referencial com o modelo (a própria vida) a partir das propriedades de registro imagético-sonoro sincrônico. Ao partir da realidade vivida cotidianamente diferentemente de uma criação narrativa que se pauta na folha em branco - tais cineastas propõem um tipo de autobiografia cuja representação de si e do mundo ao redor dependeria, menos exclusivamente, de introspecção.

Em 1977, Pincus publica um artigo no qual discorre sobre as atividades de pesquisa e de produção cinematográficas que aconteciam no MIT Film Section na década de 1970. Em sua análise, Pincus refletia sobre a produção autobiográfica do departamento - incluindo nela sua própria experiência da feitura de Diaries - como um desdobramento do cinema direto clássico, apresentando as características que a distinguiam. O cineasta sugeria que o "novo" momento, influenciado pelo movimento 
feminista, se apoiava em uma incursão analítica no âmbito pessoal, individual e privado. A abordagem temática, nesse caso, buscava significância em estruturas corriqueiras, não grandiosas e cotidianas. Ademais, a perspectiva autobiográfica era vista como um movimento de inversão do olhar para o "outro", próprio do cinema direto, a partir de narratividades nas quais o(a) próprio(a) cineasta se colocava, de alguma forma, à sujeição de apreciação pública. Nas palavras do autor:

\begin{abstract}
Alguns cineastas dessa nova geração, direta ou indiretamente influenciados pelo movimento feminista, começaram a achar significância no que era chamado de "pessoal"; eles começaram a evitar personalidades famosas, eventos notórios e assuntos obviamente grandiosos (...) Pela primeira vez, o cotidiano tornou-se um objeto possível. Pessoas normais em situações corriqueiras, não mais definidas por um papel social que costumavam ser a porta de entrada para tornarem-se o assunto de um filme - piloto de carros de corrida, atriz, prisioneiro, pessoa pobre, político. A justificativa para que se tornassem personagens era, frequentemente, apenas a de que tinham uma relação com o cineasta ou que eram de alguma forma acessíveis a ele. (...) Cineastas que filmaram por mais de uma década desta forma nunca foram filmados e nunca se viram neste tipo de espaço cinemático. Existe uma estranha experiência existencial a respeito de ver-se a si próprio no filme, verse da maneira que as pessoas te veem... Que experiência humilhante e degradante aparecer da mesma forma que os outros. Qual é a natureza de todas nossas vidas e nossas relações com os outros, nossas pequenas mentiras e fingimentos? (Pincus 1977, 172-173, tradução nossa)
\end{abstract}

As palavras de Pincus sugerem que cineastas ligados a tal momento do documentarismo estadunidense - incluindo ele próprio - enxergavam que a exploração autobiográfica do cotidiano, por via cinematográfica, poderia registrar características das relações interpessoais corriqueiras em um estado mais "inalterado" ou "natural”, se em comparação ao que vinha sido praticado até então. A asserção de Pincus sobre uma empreitada que poderia captar "a natureza de todas nossas vidas e nossas relações com os outros", "nossas pequenas mentiras e fingimentos," sugere a possibilidade da câmera de filmar (e do gravador de som) de registrar comportamentos humanos ligados à ordem do automático, repetível ou não-racionalizado. A exploração da cotidianidade como alicerce temático parece ir ao encontro do desejo de registrar comportamentos automáticos que fazem parte da rotina cotidiana. Rita Felski sugere que o hábito é o modo característico que as pessoas experienciam o cotidiano (2000, 81, tradução nossa). Por hábito, Felski entende não apenas uma ação, mas uma atitude: "hábitos

aniki Ensaios | Essays 
são frequentemente executados de uma maneira semiautomática, distraída ou involuntária. Alguns tipos de comportamento estão inscritos no corpo, como parte de uma memória somática profundamente enraizada" (2000, 89). Segundo a autora americana, "normalmente conduzimos nossas vidas diárias com base em inúmeras suposições não declaradas e não examinadas sobre como as coisas são, sobre a continuidade, identidade e confiabilidade de objetos e indivíduos" (Felski 2000, 93) e que, a menos que um problema específico surja para exigir nossa atenção, "raramente paramos para refletir sobre as práticas ritualizadas mundanas em torno das quais grande parte de nossa vida cotidiana é organizada" (Felski 2000, 9).

Em 1979, Stanley Cavell publica uma de suas principais obras relativas à análise da ontologia fílmica, onde cunha a noção de "automatismo": um conjunto de relações entre a natureza maquínica do aparato câmera como vetor de apreensão e reprodução da realidade em imagens e sons, em circunstâncias espaçotemporais únicas. ${ }^{6}$ Algumas das propostas de Cavell são valiosas para a noção do presente narrativo no contexto dos documentários autobiográficos. Ao dissertar sobre o trabalho criativo do cinema (e de cineastas) em relação às propriedades autômatas da câmera de filmar, Cavell sugere: "não é um desejo de poder sobre a criação (...) mas um desejo de não precisar de poder, de não ter que carregar seus fardos" (Cavell 1979, 40, tradução nossa). ${ }^{7}$

Uma relação autômata, nos moldes de Cavell, do registro cinematográfico em relação à realidade parece encaixar-se na proposta de narratividades autobiográficas que frisam a exploração de comportamentos cotidianos, ligados à ordem do ordinário e do habitual. A proposta é distinta de outras comumente encontradas em documentários autobiográficos: elementos narrativos frequentemente utilizados em tais filmes, como a narração em over em primeira pessoa, evidenciam o desejo de poder de um(a) cineasta sobre a representação de si próprio(a). Ao narrar sobre si, cineastas transpõem de dentro para fora a experiência vivida de uma maneira controlada a partir do sistema

\footnotetext{
${ }^{6} \mathrm{O}$ automatismo cavelliano apresenta aproximações à ontologia da imagem fotográfica proposta por André Bazin (2018). As aproximações e distinções das duas teorias são analisadas por Trahair (2014) em extensão.

${ }^{7}$ No original cavelliano: "[t]his is not a wish for power over creation (...) but a wish not to need power, not to have to bear its burdens."
}

aniki Ensaios | Essays 
simbólico das palavras, da racionalidade e da introspecção. Por outro lado, a exploração da noção de cotidianidade em uma chave autobiográfica parece tratar-se do desejo da construção narrativa a respeito de si na qual as circunstâncias espaçotemporais registradas, que transpõem o substrato pré-textual integrante de uma experiência de vida em dado momento, se apresentam como molde para o processo criativo. Ao enxergar o meio fílmico como capaz de transpor as minúcias que fazem parte dos comportamentos ordinários, como propõe Pincus, tais cineastas-autobiógrafos(as) enxergam na realidade cotidiana a matéria-prima para a construção de narrativas a respeito deles(as) próprios(as) - usufruem, portanto, do "desejo de não precisar de poder", ou de "não ter que carregar os fardos", como sugere Cavell, da criação artística (1979, 40, tradução nossa).

Ainda que a origem das propostas de narratividades documentárias autobiográficas ligadas à exploração do cotidiano possam ser traçadas para o âmbito da Costa Leste estadunidense na década de 1970, cineastas-autobiógrafos(as) de outros contextos nacionais e temporais lançaram mão de matérias-primas temáticas semelhantes para a criação de seus filmes. Um exemplo mais recente e advindo do continente europeu é o curta-metragem de vinte e cinco minutos Such a Nice Boy I Gave Birth To (Takiego pieknego syna urodzilam, 2000), primeiro filme do documentarista Marcin Koszałka. Esse filme obteve reconhecimento significativo no momento de seu lançamento e lançou mais propriamente a carreira de Koszałka como documentarista e diretor de fotografia.

Tanto a temática quanto os elementos narrativos empregados para a criação de Such a Nice Boy I Gave Birth To enfatizam a transposição do cotidiano como matéria-prima da proposta autobiográfica de Marcin Koszałka. O filme tematiza o dia-a-dia vivido por Koszałka no apartamento em que morava com seus pais à época de seus estudos universitários. Durante a maior parte dos vinte e cinco minutos do filme, a câmera de Koszałka registra o criticismo enérgico que seus pais têm em relação às suas escolhas de vida. Sua câmera registra a verborragia de seus pais em relação à maior parte de suas escolhas de vida: sua falta de comprometimento como estudante, a (não) serventia de sua carreira como cinematógrafo, a maneira como se diverte, sua vida social ou engajamentos amorosos, bem como sua falta de recursos financeiros. Ao assistirmos ao filme, o criticismo dos pais para com a vida do cineasta aflora como algo que é integrado à ordem do habitual e 
do repetível. Mesmo com a presença da câmera do diretor (por vezes rechaçada pelos seus pais), o entendimento é o de que aquela seria a experiência vivida por Koszałka diariamente. A noção de uma projeção "automática" do cotidiano para a lente (e o gravador) da câmera de filmar parece palpável. Ao fazer um filme sobre sua vida cotidiana, Koszałka não lança mão de nenhum tipo de narração em over e, na realidade, sua voz não é ouvida ao longo da grande maioria da narrativa - Koszałka pouco reage ou interage dialogicamente aos endereçamentos críticos de seu pai e de sua mãe. Embora tratando-se de um cenário familiar intenso, talvez traumático, que poderia ser descrito de outras maneiras (como um relato oral ou a própria narração em over), a intenção de uma narrativa autobiográfica na qual a câmera é responsável por tirar o fardo da criação, lembrando Cavell, parece ir ao encontro das intenções artísticas de Koszałka. Em momentos do filme, apenas ligar a câmera em um tripé e sentar-se no sofá junto a sua mãe, à frente da lente, parece suficiente para que a transposição da experiência cotidiana de Koszałka para o filme aconteça e, dessa forma, o conhecimento autobiográfico seja produzido. Such a good boy I gave birth to consiste, portanto, em um exemplo que remete às origens do documentário autobiográfico ao admitir que o mundo fale à câmera por si só, de maneira que o substrato pré-textual seja transbordado pelo cotidiano e se apresente de maneira suficiente a satisfazer uma aspiração autobiográfica.

\section{Temporalidade cronológica como estrutura de referência e de apoio para o registro imagético-sonoro sincrônico}

A segunda maneira a partir da qual a noção de tempo presente é manifestada em documentários autobiográficos acontece no emprego da ordem narrativa cronológica. Cineastas-autobiógrafos(as) que satisfazem suas visões artísticas a partir da ênfase do presente narrativo tendem a lançar mão de ambos os aspectos na narrativização da experiência vivida. No âmbito da tomada, a câmera de filmar percebe e registra as superfícies e os sons do mundo material em uma sucessão de instantes que mantém temporalmente uma única direção cronologicamente adiante. Existe uma relação análoga à do funcionamento do aparato câmera no âmbito da captação cinematográfica na maneira através da qual percebemos o transcorrer do mundo a partir de sentidos como a visão e a audição. A sucessão cronológica em narrativas autobiográficas é um dos elementos que 
aponta referencialmente para a experiência de fruir o mundo. Paul John Eakin, um dos principais teóricos do campo da autobiografia, sustenta que a sucessão cronológica mimetiza o modo com que percebemos eventos e transformações ao nosso redor. Ela apresenta-se como "uma manifestação da temporalidade inelutável da experiência humana" (Eakin 1988, 36, tradução nossa). À parte os meandros do pensamento, da reflexão e da introspecção, a experiência de fruir a transformação da realidade material ao nosso redor a partir dos sentidos pode ser relacionado com a direção cronológica do funcionamento do aparato câmera. Sensorialmente, portanto, tal como é impossível filmar para trás, também não podemos viver para trás.

Para além das propriedades relativas à cronologia do ato de filmar no âmbito do registro fílmico, a sensação de um presente autobiográfico é potencializada pela manutenção da ordem cronológica em uma perspectiva de construção narrativa, via montagem. A montagem cronológica dispõe uma sucessão de atos autobiográficos calcados em diferentes presentes de circunstâncias espaçotemporais da vida vivida por um(a) cineasta-autobiógrafo(a). Cada um de tais atos autobiográficos - a decisão de filmar - é regido, em uma circunstância específica, pela indeterminação e pela não-ciência de um(a) cineasta diante das possibilidades de desenvolvimento de uma situação. Cada decisão de filmar autobiograficamente no tempo presente aponta para a possibilidade de uma transformação futura. A noção de tempo agostiniano pode ser evocada mais uma vez para a compreensão de que, para além da relação especular apresentada na "visão presente das coisas presentes", o presente funda-se também na "esperança presente das coisas futuras" (Agostinho 1981, 309).

A esperança ou expectativa fundada no momento presente em direção a um desenvolvimento futuro é base epistemológica de parte do documentarismo moderno. Filmes relacionados à visão de Robert Drew e seus associados, a partir do início da década de 1960, evidenciam que a experiência do Cinema Direto estadunidense funda um tipo de documentário cuja motivação existencial reside na crença da transformação de indivíduos, situações e eventos diante da perspectiva indeterminada do desenrolar do tempo. A “indeterminação", segundo Fernão Pessoa Ramos (2020), é aspecto predominante da ética do documentário moderno na forma narrativa do Cinema Direto/Verdade. O elemento indeterminado guia a decisão de filmar diante do vislumbre da confirmação ou da quebra de uma expectativa 
que se funda no momento circunstancial, presente, de cada registro. A decisão de filmar, dessa forma, é carregada pelo valor extrínseco do potencial de transformação de um cenário retratado. A possibilidade de filmar a História sendo feita, como propunha Drew, é iniciada no momento da detecção de tal potencial de transformação. O elemento indeterminado garante a potência narrativa dos filmes mais simbólicos do Cinema Direto e pode ser descrito: haverá sucesso ou insucesso nas empreitadas de John Kennedy como candidato democrata à presidência, em Primárias (Primary, Robert Drew, 1960)? Sucumbirá a carreira do vendedor de bíblias Paul Brennan diante de uma transformação no modo de negócios e de um novo modelo econômico estadunidense, em Caixeiro-Viajante (Salesman, Albert Maysles, David Maysles e Charlotte Zwerin, 1969)? A montagem cronológica no caso dos dois filmes resulta no movimento sequencial das expectativas fundadas em cada circunstância de registro, apresentando suas sucessivas frustrações ou confirmações, em direção a um desfecho narrativo.

A noção de um presente projetado cronologicamente para o futuro é trazida para uma perspectiva autobiográfica pouco tempo depois e advém, também, do contexto da produção do MIT Film Section. Ao apresentarem características intrínsecas de (auto)reflexividade da figura do(a) cineasta para o eixo temático, filmes autobiográficos frustraram elementos fundantes do Cinema Direto clássico, como a proposta não-interventiva e de recuo observativo da câmera. Mesmo com a volta da câmera para a figura do(a) realizador(a) a partir de elementos como a interação, a participação e o dialogismo com as situações e pessoas que são retratadas, a ênfase no presente narrativo e em macroestruturas cronológicas em alguns desses filmes relaciona-os com preocupações semelhantes à do Cinema Direto. ${ }^{8}$

Em documentários autobiográficos que frisam o tempo presente e a disposição narrativa cronológica, cineastas-autobiógrafos(as) frequentemente detectam situações específicas das próprias vidas na qual existe potencialidade de transformação. Nesses casos, o ímpeto autobiográfico inicial (o próprio desejo de realizar o filme) alicerça-se na crença diante da ação do tempo em relação a aspectos da existência

\footnotetext{
${ }^{8}$ Detalho os movimentos de desdobramento do cinema direto clássico para o documentário autobiográfico em outro artigo, publicado anteriormente (Tonelo 2018).
}

aniki Ensaios | Essays 
do(a) cineasta, cujos desfechos são impossíveis de antever. A potência de tais narrativas apoia-se no entendimento, da parte dos espectadores, de que existe o desejo de um(a) cineasta em compartilhar determinado aspecto de sua vida individual que podemos julgar como definidora para uma existência que é vivida para além do registro cinematográfico - e que, semelhantemente a eventos marcantes de nossa própria vida, os(as) cineastas não têm a certeza sobre os rumos que esses podem tomar.

A diferença que existe entre os documentários autobiográficos e o modelo do cinema direto clássico reside na aproximação (ou fusão) da figura do cineasta com o objeto (o assunto) da narrativa fílmica. No caso do primeiro, como espectadores, entendemos que Robert Drew e seus associados estavam próximos ao presidente John F. Kennedy nas circunstâncias de filmagem das narrativas mencionadas com o intuito de fazer um filme e que, caso não houvesse tal intuito, tais eventos não fariam parte da vida que os cineastas levam para além do ofício. Em documentários autobiográficos, por outro lado, o intuito fílmico e da decisão de cada circunstância do registro sobrepõe-se à própria vida muitas vezes em momentos significativos da vida individual de uma ou qualquer pessoa. Nesse sentido, o substrato pré-textual apresenta maior densidade na percepção de tais filmes. Como espectadores, entendemos que a situação crítica pertencente à vida dos(as) cineastasautobiógrafos(as) poderia ser vivida independentemente do registro e, no entanto, é compartilhada. Às decisões que permeiam o próprio tecido da existência cotidiana é adicionada a decisão de filmar. A vida e a possibilidade de registro correm em linhas paralelas, tocando-se e sobrepondo-se em circunstâncias espaçotemporais que entendemos como atos autobiográficos. Disposta cronologicamente, a narrativa autobiográfica apresenta o desenvolvimento de uma situação rumo a um desfecho ou sugerindo o vislumbre de uma vida que continuará sendo vivida para além do término da narrativa.

O desenvolvimento narrativo cronológico diante do desenrolar indeterminado de uma situação é frequentemente antevisto no próprio desenho de um projeto autobiográfico. O caso de Silverlake Life: The View from Here (Tom Joslin e Peter Friedman, 1993), mencionado na introdução deste estudo, pode ser trazido à tona novamente. No filme, o ímpeto autobiográfico de Tom Joslin foi propulsionado pela constatação, pelo cineasta, do agravamento dos sintomas do vírus da AIDS em seu corpo. A partir desse momento, Joslin registra a partir de 
sua câmera de vídeo as transformações trazidas pela situação crítica em seu corpo e na vida cotidiana que leva com o parceiro, Mark Massi. No filme, é premente o senso de indeterminação de Joslin, em cada um de seus registros fílmicos, diante da evolução da doença. O elemento indeterminado, no caso de Joslin, potencializa o desejo de cristalização do presente em cada circunstância filmada em virtude do espectro de uma morte que poderia ou não acontecer - como consequência da doença ou de uma possível resposta de seu corpo aos tratamentos a que se submetia. Em Silverlake Life, o registro das circunstâncias presentes projeta-se de maneira acentuada em direção à posterioridade quando sua situação clínica se agrava e, assim, a possibilidade da morte torna-se mais palpável. O filme de Joslin é um dos poucos casos em que a morte do cineasta-autobiógrafo é parte da própria narrativa - implicando, assim, a necessidade de estratégias, tomadas por terceiros, para a finalização do filme.

Em um exemplo mais recente, First Comes Love (2013), a cineasta Nina Davenport - também pertencente à tradição de Cambridge de documentários autobiográficos, tendo sido aluna de Ross McElwee evidencia como o substrato pré-textual se manifesta como força propulsora do desejo de criar uma narrativa autobiográfica. O filme tematiza o momento em que Davenport, aos 40 anos de idade e sem manter um relacionamento amoroso, deseja engravidar pela primeira vez. A decisão de Davenport de tentar tornar-se mãe em tais circunstancias é concomitante ao início de seus registros fílmicos. No filme, a vibração do presente narrativo é sentida a partir dos registros cinematográficos de cada etapa do momento decisivo da vida da cineasta. Em cada um dos registros são evidenciadas tanto as potencialidades de transformação na vida da cineasta quanto as possíveis frustrações de expectativas (fruto da indeterminação) que as regem: o pedido da cineasta para que seu melhor amigo seja o doador de esperma (que encontra certa resistência ao longo do filme); a nãoreceptividade inicial do pai da cineasta em relação à empreitada (posteriormente modificada); o processo de reposição hormonal e fertilização in vitro; o resultado positivo da gravidez e a transformação do corpo da cineasta; e, enfim, o parto de seu primeiro filho, Jasper, que é registrado e usado na narrativa. Como nos outros exemplos mencionados, a ordem cronológica em First Comes Love é utilizada como meio de narrativização de sucessivas circunstâncias da vida de Davenport que, marcadas pela não-ciência da própria cineasta em 
relação aos resultados da empreitada, colocam o presente como meio de sustentação narrativa em direção a um futuro indeterminado.

\section{Interação dialógica entre cineasta e pessoas filmadas como manifestação do presente autobiográfico por meio da emersão de afetos.}

Finalmente, uma terceira manifestação do tempo presente em narrativas autobiográficas consolida-se a partir da transposição dos laços afetivos que existem entre o(a) cineasta-autobiógrafo(a) e as pessoas filmadas no momento do registro. A emersão da relação afetiva entre as partes acontece de maneira dialógica ou interativa na circunstância da tomada fílmica. Em documentários que sublinham o tempo narrativo presente, a transposição do afeto entre cineasta e pessoas filmadas irrompe, ainda que flexionada pela presença da câmera, remetendo ao substrato pré-textual que pertence à vida do(a) cineasta-autobiógrafo(a) na circunstância espaçotemporal do registro.

O eixo temático-narrativo de documentários autobiográficos é frequentemente composto por relações dialógicas entre o(a) cineastaautobiógrafo(a) e pessoas com quem ele(a) mantém uma associação íntima e/ou familiar - cônjuges, mãe, pai, filhos(as), irmãos ou irmãs. Por relação dialógica entendem-se os tratos conversacionais, entre o(a) cineasta e tais pessoas, que ocorrem na circunstância da tomada fílmica. A relação dialógica entre as partes ocorre através de estratégias narrativas de natureza autorreflexiva. Entre elas, a utilização narrativa da voz do(a) cineasta posicionado(a) corporalmente no extracampo fílmico - como se vinda por detrás da câmera - em uma posição de interlocutor; ou a incorporação de momentos em que o diálogo entre cineasta e pessoa filmada ocorre quando o corpo de ambos é visível no quadro - a partir, por exemplo, da utilização do tripé.

A emersão dos laços afetivos entre cineasta e pessoas filmadas em uma relação dialógica depende da captação de som sincrônico à imagem em movimento na circunstância da tomada fílmica. No mesmo sentido em que inovações tecnológicas relativas à possibilidade de registro cinematográfico imagético-sonoro sincrônico foram peças-chave para o desenvolvimento epistemológico do documentário moderno, suas aplicações no contexto dos documentários autobiográficos possuem historicidade própria. Embora não se trate de condição imprescindível, a incorporação fílmico-metodológica de uma equipe-de-uma-pessoa só 
- o(a) cineasta solo como responsável pelo registro imagético e sonoro - é a principal de tais aplicações. Trata-se de uma estratégia metodológica e narrativa que potencializa a emersão da relação afetiva entre cineasta e pessoas filmadas em um contexto autobiográfico. Seu desenvolvimento também está ligado ao contexto das pesquisas do MIT Film Section. Ed Pincus (1972 e 1977) descreveu detalhadamente o workflow que vinha sido desenvolvido no departamento e sua aplicação no contexto de Diaries (1971-1976).

Em tal configuração há um trato singular, mediado pela câmera, no que tange à flexão do comportamento tanto da pessoa filmada quanto do cineasta, dependendo da relação familiar existente entre eles. Em tais casos, a noção de um presente autobiográfico é evocada na medida em que a relação dialógica entre cineasta e pessoa filmada transpõe uma relação afetiva pertencente à experiência pré-textual do(a) cineasta naquela situação específica. As relações comportamentais impulsionadas pelos laços familiares e afetivos tornam-se parte inexorável de toda encenação proveniente. Em tal cenário, expressões físicas como as palavras pronunciadas, mas também os gestos, as feições e os silêncios adquirem relevância e significado na maneira em que lemos a interação entre cineasta e uma pessoa próxima de si.

À tradicional relação de poder entre cineasta e pessoa filmada adicionam-se os sentimentos (de ambas as partes) que regem a relação pré-textual entre eles: afeto, carinho, cuidado e respeito; ou, na outra ponta do espectro, decoro, autoridade e pavor. Semelhantemente à noção de cotidianidade, nesses casos, a câmera de filmar é responsável por apontar para a realidade que é vivida por um(a) cineasta no momento do registro, e por fazer dela a matéria-prima autobiográfica. O dialogismo entre cineasta e pessoa filmada evoca, portanto, não apenas uma circunstância espaçotemporal determinada, mas a relação afetiva particular entre ambos que aflora na tomada fílmica. Pelo fato de tais filmes frequentemente, como já mencionado, estabelecerem narrativamente laços entre cineasta e pessoas próximas de si há um jogo entre ver e ser visto que, possibilitado pela câmera de filmar, emerge como possibilidade de uma criação autobiográfica relacional o que Susanna Egan nomeia como "autobiografia como interação" (Egan 1994). Em outras palavras, um(a) cineasta que filma seu filho desempenha na tomada o papel de documentarista $e$ de pai (mãe), ao mesmo tempo que o filho desempenha o papel de pessoa filmada $e$ de filho. Os devidos acúmulos destas responsabilidades flexionam 
singularmente o tête-à-tête entre as partes que testemunhamos como espectadores. Michael Renov explica tal relação ao expor o conceito de "Etnografia Doméstica". Renov sustenta que a consanguinidade e a co(i)mplicação entre sujeito e objeto são seus fatores determinantes: "Porque as vidas do artista e do objeto são interlaçadas a partir de laços sanguíneos ou comunais, a documentação da vida de um tende a implicar o outro de maneiras complicadas" (Renov 2004, 218, tradução nossa).

Diversos documentários autobiográficos das últimas decádas apresentam a co(i)mplicação entre sujeito e objeto, segundo os termos de Renov, como matéria-prima da construção narrativa. A estratégia metodológica do sync-sound one-person-crew aplicada às interações dialógicas entre cineasta e pessoa filmada é fundamental para o afloramento da relação afetiva entre as partes e seu uso como subsídio narrativo-autobiográfico. Tal característica é evidenciada na carreira de um cineasta como Ross McElwee, na trajetória entre Time Indefinite (1993) e Photographic Memory (2011), a partir da tematização do contínuo distanciamento entre o diretor e seu primeiro filho, Adrian. Outros exemplos recentes podem ser mencionados. No filme estadunidense Tell Them Who You Are (Mark Wexler, 2004), a relação díspar e ideologicamente diversa entre pai e filho aflora no retrato que Mark Wexler tenta realizar de seu pai, o famoso cineasta e diretor de fotografia Haskell Waxler. Já em Os Dias Com Ele (Maria Clara Escobar, 2012), um caso mais comentado da filmografia brasileira, evidencia-se a relação austera e distante entre a cineasta e seu pai e uma disputa pelo controle da narrativa e pelo teor do conhecimento evocado pelo filme na intersecção entre o público e o privado. Mais recentemente, pode-se destacar Limiar (2020), de Coraci Ruiz, que, no ano de 2021, está sendo exibido no circuito internacional de documentários. Filmado ao longo de três anos, o filme de Ruiz tematiza o processo que leva à transição de gênero do filho da cineasta, Noah. Nota-se, em Limiar, a maneira como os papéis de mãe/cineasta e filho/pessoa filmada afloram, ao mesmo tempo que se acumulam, nas interações, imbuídas em uma circunstância definidora para a vida de ambos. No filme, o desenvolvimento narrativo cronológico evidencia a mudança de perspectiva de ambos - alicerçada no laço familiar existente - em relação ao processo de transição de gênero de Noah. Um filme como Limiar demonstra como os documentários autobiográficos podem aflorar, a partir de cada registro imagético-sonoro, uma cristalização de afeto que, enquanto espectadores, reconhecemos que perdura 
imediatamente antes e imediatamente após o registro cinematográfico. Por ser presente e apontar para uma circunstância presente, tal relação pode modificar-se ao longo do tempo. A modificação pode ser visível no decorrer da própria narrativa. Nesses casos, a estrutura de desenvolvimento cronológico em um filme autobiográfico evidencia a transformação do afeto com o passar do tempo.

\section{Considerações finais}

Este artigo procurou explicitar como a noção de tempo presente se manifesta em narrativas documentárias de teor autobiográfico. Tais manifestações estão relacionadas de maneira íntima com a história do documentário moderno, na medida em que se apresentam como desdobramentos de debates que permearam o cinema documentário desde os anos 1960. No final da década, as possibilidades de registros imagéticos-sonoros sincrônicos de maneira mais acessível encontram um terreno ideológico favorável para a criação de narrativas que visavam explorar tematicamente questões que remetiam ao universo privado e/ou doméstico dos(as) cineastas. Alguns dos estudos originários de tal cruzamento têm lugar na produção realizada na Costa Leste dos Estados Unidos no âmbito universitário de instituições como o MIT Film Section. Desde então, cineastas-autobiógrafos(as) de outras localidades utilizaram as manifestações do tempo presente como subsídio para a narratividade autobiográfica.

No artigo, identifiquei a manifestação do presente em narrativas autobiográficas a partir de três principais perspectivas: a exploração da cotidianidade como subsídio temático; a ordem cronológica como organização narrativa; e a relação dialógica entre cineasta e pessoas filmadas como meio de afloramento dos laços existentes entre ambos nas circunstâncias da tomada fílmica. Como mencionado, mais de uma de tais perspectivas de exploração do tempo presente podem estar interseccionadas em uma mesma narrativa. Ademais, a exploração do presente em narrativas documentárias autobiográficas não consiste em uma "modalidade" - segundo a expressão cunhada por Michael Renov - distinta da narrativização a respeito de si, podendo estar presente em documentários autobiográficos estilisticamente diversos.

Como consideração final a este estudo, sustento que a exploração do presente em narrativas autobiográficas não necessariamente alicerça de 
maneira integral o conjunto estilístico e metodológico que pertence à proposta artística de um(a) cineasta. O caso de Diaries (1971 - 1976) foi usado recorrentemente como sustentação para a análise devido ao fato de que o filme de Ed Pincus - assim como seus escritos à época comprova como o cineasta almejava sublinhar o teste explorativo das manifestações do presente em sua narrativa a respeito do desenvolvimento de sua vida pessoal, familiar, matrimonial e social ao longo dos cinco anos de sua empreitada. Diaries consiste, neste sentido, em um exemplo de como as perspectivas do presente autobiográfico (cotidianidade, cronologia, interação dialógica) são levadas a cabo em uma mesma narrativa. A proposta artística de um cineasta como Ross McElwee ao longo de sua carreira, por outro lado, evidencia como a exploração do presente em narrativas autobiográficas pode estabelecerse como um dos pilares das estratégias estilísticas e metodológicas de um cineasta-autobiógrafo. Como produtos artísticos de um sujeito integrante do momento histórico do MIT Film Section, os filmes de McElwee evocam o emprego de metodologias próximas ao cinema direto/vérité interativo que remetem às pesquisas que aconteceram no seu departamento. Tal perspectiva, contudo, é aliada à outra: a exploração de uma voz over meditativa, frequentemente relacionada a eventos pretéritos da vida do diretor evocados pela utilização de trechos de seus filmes anteriores, em um novo momento presente. A relação simbiótica entre ambos pilares metodológicos - a exploração vérité e o emprego meditativo, reflexivo e frequentemente retrospectivo de sua voz over - é, justamente, o elemento garantidor do conjunto narrativo-metodológico pelo qual McElwee se tornou reconhecido.

Finalmente, a exploração do tempo presente em documentários autobiográficos - por meio das perspectivas destacadas neste estudo como a cotidianidade, a ordem cronológica e a interação dialógica entre cineasta e pessoas filmadas - não é um elemento indissociável das narratividades a respeito de si no cinema de não-ficção. Tampouco se trata de um conjunto estilístico-metodológico que, caso ausente, colocaria em xeque uma espécie de autenticidade da proposta artística de determinado(a) cineasta-autobiógrafo(a). Como frisado ao longo do artigo, a exploração do presente em tais narrativas sustentou a visão artística de cineastas que testaram criativamente possíveis alternativas à autobiografia em seu caráter retrospectivo - lembrando, novamente, Phillipe Lejeune - a partir das materialidades oferecidas pelo documentário em sua virada moderna. Não é o caso, por exemplo, de 
um filme como As Praias de Agnès, cujo lugar de destaque no imaginário a respeito dos documentários autobiográficos é inquestionável. Em seu filme, Agnès Varda não apenas se apoia no caráter retrospectivo como garantidor do ímpeto autobiográfico naquele momento de sua vida, mas também se distancia estilistica e metodologicamente do cerne das preocupações artísticas de cineastas que visam uma exploração do tempo presente como subsídio da narratividade a respeito de si, cujos funcionamentos e principais perspectivas busquei analisar ao longo do texto.

\section{Agradecimentos}

Este trabalho contou com o apoio da Fundação de Amparo à Pesquisa do Estado de São Paulo (FAPESP), através das bolsas \#2018/12740-2 e \#2019/17689-8.

\section{Referências}

Abrash, Barbara. 2007. The View from the Top: P.O.V. Leaders on the Struggle to Create Truly Public Media. Washington D.C.: American University Center for Social Media.

Agostinho, Santo. 1981. Confissões. Porto: Livraria Apostolado da Imprensa.

Bazin, André. 2018. "Ontologia da imagem fotográfica." Em: O que é o Cinema? Trad. Eloisa Araújo Ribeiro, 27-35. São Paulo: Ubu Editora.

Cavell, Stanley. 1979 [1971]. The World Viewed: Reflections on the Ontology of Film. Cambridge: Harvard University Press.

Eakin, Paul John. 1988. "Narrative and Chronology as Structures of Reference and the New Model Autobiographer." Em: Studies in Autobiography, ed. por James Olney, 32-41. Nova Iorque e Oxford: Oxford University Press.

Egan, Susanna. 1994. "Encounters in Camera: Autobiography as Interaction." Modern Fiction Studies 50 (3): 593-618.

Felski, Rita. 2000. Doing Time: Feminist Theory and Postmodern Culture. Nova Iorque: NYU Press. 
Gernalzick, Nadja. 2014. "Lives and Deaths in Photographic Tense: Temporality and Filmic Automediality After the Indexical Turn." a/b: Auto/Biography Studies 29 (2), 225-248.

Lane, Jim. 2002. The Autobiographical Documentary in America. Madison: The University of Winsconsin Press.

Lejeune, Philippe. 2008. O pacto autobiográfico: De Rousseau à Internet. Belo Horizonte: Editora UFMG.

MacDonald, Scott. 2013. American Ethnographical Film and Personal Documentary: The Cambridge Turn. Londres e Los Angeles: University of California Press.

Pincus, Ed. 1972. "One Person Sync-sound: A New Approach to Cinema Vérité.” Filmmakers Newsletter 6 (2): 24-30.

Pincus, Ed. 1977. "New Possibilities in Film and the University." Quarterly Review of Film Studies 2 (2): 159-178.

Ramos, Fernão Pessoa. 2012. “A Mise-en-scène do documentário: Eduardo Coutinho e João Moreira Salles." Rebeca: Revista brasileira de estudos de cinema e audiovisual 1 (1): 16-53.

Ramos, Fernão Pessoa. 2020. “Como é que é 'ver através' uma fotografia?.” Eco-Pós 23 (3): 422-447.

Renov, Michael. 2004. The Subject of Documentary. Minneapolis: University of Minnesota Press.

. 2014. "Filmes em primeira pessoa: Algumas proposições sobre a autoinscrição.” Em: Silêncios históricos e pessoais: Memória e subjetividade no documentário latino-americano contemporâneo, organizado por Natalia Barrenha e Pablo Piedras. Campinas: Medita.

Russell, Catherine. 1999. Experimental Ethnography: The Work of Film in the Age of Video. Durham e Londres: Duke University Press.

Tonelo, Gabriel. 2018. "Os filmes e o pensamento de Ed Pincus: o Cinema Direto em direção à autobiografia.” Doc-Online 23: 129157.

Trahair, Lisa. 2014. "Being on the Outside: Cinematic Automatism in Stanley Cavell's The World Viewed." Film-Philosophy 18 (1): 128-146. 


\section{Filmografia}

As Praias de Agnès. Dir. Agnès Varda. Ciné-tamaris, Arte France Cinéma e Canal+, França, 2008, 112 min.

Diaries (1971 - 1976). Dir. Ed Pincus. Cambridgeport Films, Estados Unidos, 1982, $200 \mathrm{~min}$.

First Comes Love. Dir. Nina Davenport. Nina Davenport Productions, Estados Unidos, 2013, 105 min.

Limiar. Dir. Coraci Ruiz. Laboratório Cisco, Brasil, 2020, 77 min.

Os Dias com Ele. Dir. Maria Clara Escobar. Filmes de Abril, Klaxon Cultura Audiovisual, Brasil, 2012, 105 min.

Photographic Memory. Dir. Ross McElwee. St. Quay Films et al, Estados Unidos, 2011, $87 \mathrm{~min}$.

Primary. Dir. Robert Drew. Drew Associates, Estados Unidos, 1960, 60 $\min$.

Salesman. Dir. Albert Maysles, David Maysles e Charlotte Zwerin. Maysles Film, Estados Unidos, 1969, 91 min.

Sherman's March. Dir. Ross McElwee. Homemade Movies et al, Estados Unidos, 1986, $157 \mathrm{~min}$.

Silverlake Life: The View from Here. Dir. Tom Joslin e Peter Friedman. Peter Friedman e Channel 4, Estados Unidos, 1993, 99 min.

Strong Island. Dir. Yance Ford. Yanceville Films et al, Estados Unidos, 2017, $107 \mathrm{~min}$.

Takiego pieknego syna urodzilam. Dir. Marcin Koszałka. Telewizja Polska (TVP), Polônia, 2000, 25 min.

Tell Them Who You Are. Dir. Mark Wexler. Wexler's World, Estados Unidos, 2004, 95 min.

Time Indefinite. Dir. Ross McElwee. Homemade Movies et al, Estados Unidos, 1993, 114 min.

Tongues Untied. Dir. Marlon Riggs. Signifyin' Works, Estados Unidos, 1989, $55 \mathrm{~min}$.

Valsa com Bashir. Dir. Ari Folman. Bridgit Folman Film Gang, Les Films d'Ici, Razor Film Produktion GmbH, Israel, 2008, 90 min.

Varda por Agnès. Dir. Agnès Varda. Ciné-tamaris, ARTE, França, 2019, 119 min.

aniki Ensaios | Essays 
Visages, Villages. Dir. Agnès Varda e JR. Ciné-tamaris, Social Animals, Rouge International, França, 2017, 94 min.

\title{
To Film Oneself Being: The narrative present tense in autobiographical documentaries
}

\begin{abstract}
This article discusses how a narrative "present tense" is transposed to autobiographical and personal documentaries. Films in which filmmakersautobiographers seek to transpose the "present" of a lived experience through synchronic sound-image methodologies have been part of the history of documentary film since the late 1960s. Aspects of the transposition of an autobiographical present tense, however, still permeate the contemporary filmography of different countries. The article explains such transposition of a present time in autobiographical narratives through three perspectives: (1) the everyday life as thematic material of the autobiographical narrativity; (2) the chronological temporality as reference and support structure for the autobiographical narrative; (3) the dialogical interaction between filmmaker and filmed people as manifestation of the autobiographical present through the emergence of affective bonds.
\end{abstract}

KEYWORDS Autobiographical documentary; temporality; narrative; chronology; direct cinema.

Recebido a 04-02-2021. Aceite para publicação a 12-09-2021.

aniki Ensaios | Essays 